\title{
Prevalence of Mycobacterium avium subsp. paratuberculosis infection in sheep flocks from three regions of Antioquia, Colombia
}

\author{
Miguel Hernández-Agudeloa ${ }^{a}$ Bernardita Collado ${ }^{\mathrm{b}}$, Carlos Tejeda ${ }^{\mathrm{b}}$, Nicolás F. Ramírez-Vásquez ${ }^{\mathrm{a}}$, \\ Jorge A. Fernández-Silva ${ }^{a}$, Miguel A. Salgado ${ }^{b^{*}}$
}

\begin{abstract}
Paratuberculosis or Johne's disease is a slow-developing infectious disease caused by Mycobacterium avium subsp. paratuberculosis (MAP) affecting mainly domestic ruminants and producing a significant economic threat to livestock production systems. Although reports on paratuberculosis in small ruminants in Colombia are very scarce, the Colombian sheep industry has identified paratuberculosis as one of the causes of its low development. There have been reports of MAP infection in sheep flocks, mainly in the Cundiboyacense Plateau and the Bogotá savannah, but the prevalence of MAP infection in sheep and goat populations in Colombia is yet unknown. Therefore, the present study aimed to accurately estimate the prevalence of MAP infection at flock level in a sheep population of 24 flocks located in three regions of the province of Antioquia, Colombia. ELISA test as well as culture and direct qPCR were used as diagnostic tools. Overall, 456 blood serum samples were analysed and at least one seropositive animal was found in 17 (70\% IC: 51.2-0.90) out of the 24 study flocks and, in total, 37 animals showed positive ELISA results (8\% IC: 5.5-10.5). Regarding MAP direct detection, 90 faecal pools from the 24 flocks were cultured and subjected to qPCR diagnosis. Both direct qPCR and culture detected 25 (27.7\%) and 64 (71.1\%) faecal pools as MAP positive, respectively. More specifically, MAP positive pools were detected in $45.8 \%$ (IC: $24.3-67.3$ ) and $83.3 \%$ (IC: $67.3-99.3$ ) of the flocks by direct qPCR and culture, respectively. MAP infection is widespread in sheep flocks in the study regions and the combination of several diagnostic tests was necessary to achieve a more accurate and precise infection detection of this important pathogen.

Key words: Paratuberculosis, prevalence, Johne's disease, small ruminant.
\end{abstract}

\section{INTRODUCTION}

Mycobacterium avium subsp. paratuberculosis (MAP) is one of the most fastidious members of the Mycobacterium genus. It is the causal agent of Johne's disease (also known as paratuberculosis) which is an untreatable disease characterized by granulomatous enteritis, diarrhoea, loss of body weight and death (Chiodini 1993).

Although it is generally assumed that this infection occurs similarly in all domestic ruminant species, there is sufficient evidence to suggest that MAP infection in small ruminants is different to that in cattle, both in the clinical form as well as the MAP strains involved (Clarke 1997).

The disease is responsible for significant economic losses to livestock production worldwide (Sweeney 2011, Garcia and Shalloo 2015). Additionally, a zoonotic potential has been proposed since MAP has been consistently found in humans with Crohn's disease (Zarei-Kordshouli et al 2019). Furthermore, an increasing number of diseases such as Blau syndrome, type 1 diabetes, Hashimoto thyroiditis and multiple sclerosis have also been associated to MAP presence, reinforcing the zoonotic potential of this pathogen (Lee et al 2011, Sechi and Dow 2015).

Received: 06.07.2020.

Accepted: 07.09.2020.

${ }^{a}$ Grupo Centauro, Escuela de Medicina Veterinaria, Facultad de Ciencias Agrarias, Universidad de Antioquia, Medellín, Colombia.

bInstituto de Medicina Preventiva Veterinaria, Facultad de Ciencias Veterinarias, Universidad Austral de Chile, Valdivia, Chile.

*Corresponding author: MA Salgado; Edificio Pugin $5^{\circ}$ piso, Campus Isla Teja, Valdivia, Chile. miguelsalgado@uach.cl
Some research on MAP infection in Colombia has been reported for small ruminants (Mogollón et al 1983, Mancipe et al 2009, Hernández et al 2017), but information on the presence and distribution of this infection is still scarce and the true prevalence (TP) of MAP infection in sheep populations in Colombia is clearly unknown. However, the Colombian sheep industry has identified paratuberculosis as one of the causes of the low development of the industry, limiting meat commercialization at national and international levels (Castellanos et al 2010). Unfortunately, there are currently no programs regarding the prevention and control of MAP infection for sheep populations in Colombia.

The lack of a prevalence estimate not only limits the capacity to assess the real impact of this important infectious disease, but also limits the capacity to allocate sufficient resources for its control precluding an adequate monitoring of the effectiveness of potential control measures. Since neither the Colombian sheep industry nor the Colombian government have estimates on the TP of MAP infected flocks, we aimed to accurately estimate the flock level prevalence of MAP infection and also to explore flock level risk factor associated with the presence of MAP antibodies in these sheep flocks located in the Antioquia province, Colombia.

\section{MATERIAL AND METHODS}

\section{STATEMENT OF ANIMAL RIGHTS}

The authors declare that the present study does not contain clinical studies or patient data. Informed consent 
was obtained from all individual participants included in the study. The study was conducted according to the current law of animal protection in Colombia and was approved by the Ethics Committee for Animal Experimentation of the Universidad de Antioquia, Colombia (Act 111, May 2017).

\section{ANIMAL POPULATION AND STUDY DESIGN}

A cross sectional study was carried out using ELISA test as well as faecal culture and direct qPCR as diagnostic tools to assess MAP infection prevalence in this animal population and to explore the influence of multiple flock management practices associated with MAP seroprevalence (figure 1).

To avoid a possible selection bias and taking into account that in the province of Antioquia there were no official records of sheep flocks, a census to identify each sheep farm located in the study region was carried out before selecting the participants. According to this, the whole sheep population located in the Metropolitan Area, the Northern, and the Eastern region of the Province of Antioquia, Colombia, were the sample frame of the present study $(n=2,479)$.

As a result of this search, 25 sheep farms were identified but one refused to participate in the study. All remaining sheep farmers agreed to participate, permitting the sampling and the interview $(n=24)$ to take place. The Metropolitan Area region, the Northern region, and the Eastern region of the Province of Antioquia, Colombia were selected as the study regions due to their increase in sheep production in recent years and proximity to Medellín city, which is the nearest and main sheep consumption market.

The only inclusion criterion for sampling was that animals must be over one year of age. A representative sample of this animal population was taken following a multistage sampling procedure, in which a constant proportion of animals was taken from each flock (Dohoo et al 2010). The sample size calculation allowed an error of $5 \%, 95 \%$ confidence, and expected prevalence of $50 \%$. According to this, the sample size was estimated at 384 animals. In each study participant flock, $20 \%$ of the animals over one year of age was randomly sampled. In those flocks with less than 20 animals over one year of age, only five animals were sampled in order to complete at least one single faecal pool. In total, 456 animals were sampled in selected flocks.

\section{DATA AND SAMPLE COLLECTION}

Between August and September 2017, each of the 24 sheep flocks was visited once for data and sample collection. Overall, blood and faecal samples were collected from

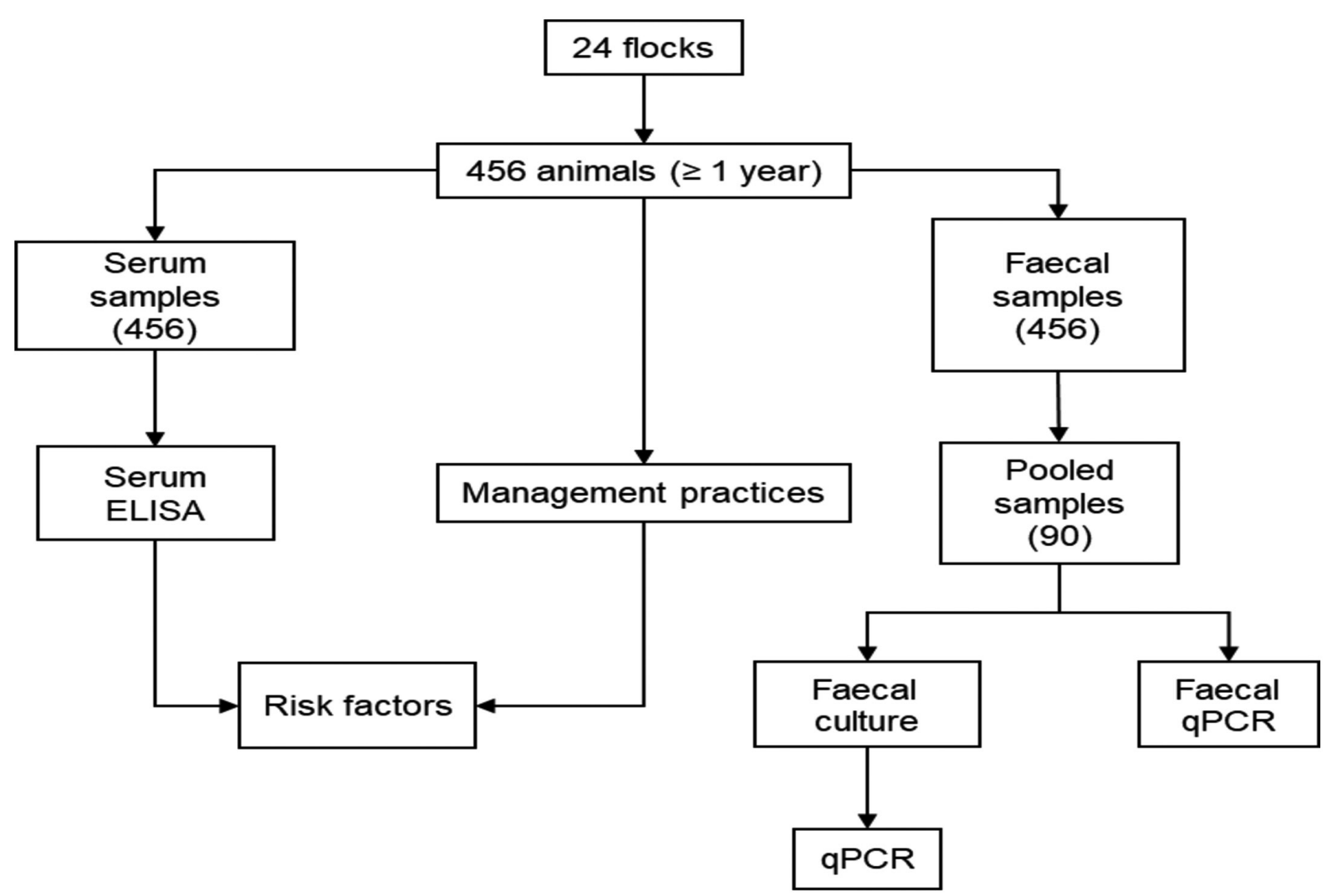

Figure 1. Overview of the study design for the determination of MAP prevalence in 24 sheep flocks of three regions of Antioquia, Colombia. 
456 sheep of the 24 participating flocks. Available data regarding flock management practices were collected using a questionnaire, the same day in which blood and faecal samples were collected. The information was obtained from the flock manager or flock owner. All questionnaires included an introductory paragraph explaining the rationale and importance of the questions, how data was going to be used, and a confidentiality agreement. The questions were divided into three sections: 1) general information of the herd, 2) herd management practices, and 3) knowledge about the disease. Questions were read out to the farmer and answers were selected from multiple closed responses or otherwise written down. The questions searched for MAP infection transmission risk factors in ruminants, for example: shared roads between neighbouring flocks (Dhand 2007), presence of different species of ruminants in the same flock (Al-Majali et al 2008), co-grazing between cattle and goats or sheep (Çetinkaya et al 1997), community grazing, poor control of intestinal parasites (Angelidou et al 2014) and animal trade between related flocks (Marquetoux 2016).

\section{DIAGNOSTIC TESTS}

Enzyme-linked Immunosorbent Assay (ELISA). Blood samples were taken from the jugular vein using Vacuette ${ }^{\circledR}$ tubes of $7 \mathrm{~mL}$ without anticoagulant (Greiner Bio-one,

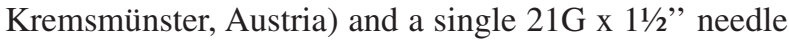
per animal, after local cleaning and disinfection with antiseptic alcohol. After collection, the blood samples were left to stand at room temperature to allow clot retraction. Subsequently, each sample was centrifuged at 2000-2500 rpm for 3-5 minutes to ease the serum extraction. The serum obtained was kept refrigerated until arrival at the Diagnostic Unit of the Facultad de Ciencias Agrarias, Universidad de Antioquia in Medellin, Colombia, where it was frozen at $-20{ }^{\circ} \mathrm{C}$ until analysis by ELISA in October 2017. The presence of antibodies against MAP in the blood serum samples was determined by ELISA using the commercial diagnostic kit CATTLETYPE® MAP Ab (Qiagen, Leipzig, Germany) according to manufacturer guidelines.

The test characteristics of the ELISA assays used in this study, which are licensed in Germany for the detection of antibodies against Mycobacterium avium subsp. paratuberculosis in cattle, are sensitivity $59.1 \%$ and specificity $98.6 \%$, determined by the Friederich Loeffler Institut, National Reference Laboratory for Paratuberculosis, using the reference panels for serum and milk of the NRL for paratuberculosis.

Culture. From each of the 456 study animals, a faecal sample (2-5 g) was taken with a new clean glove directly from the rectum. No animals had been vaccinated against MAP infection and researchers were unaware of their historical infectious status or the status at the time of sampling. The samples were kept refrigerated until arrival at the laboratory. To overcome the high costs of faecal culture, faecal samples of individual animals were pooled at the laboratory. Therefore, individual faecal samples of five animals from the same flock were pooled in a new sterile container (Fiorentino et al 2012, Mita 2016). Briefly, each faecal sample (2-5 g) from the study animals was homogenised in a sterile container. The pools $(n=90)$ were frozen at $-80^{\circ} \mathrm{C}$, then shipped to the Laboratorio de Enfermedades Infecciosas, Instituto de Medicina Preventiva Veterinaria, Universidad Austral de Chile, Valdivia, Chile at $4^{\circ} \mathrm{C}$ allowing the slow defrosting of samples. On arrival, samples were immediately refrigerated and processed by both culture and direct MAP qPCR detection within the following hours. Pool faecal samples were

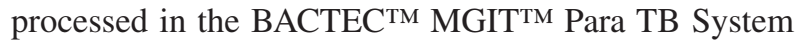
(BD Diagnostic Systems, Franklin, NJ, USA), according to the manufacturer's instructions. Each inoculated MGIT tube was inserted into an MGIT 960 instrument (BD Diagnostic Systems, Franklin, NJ, USA) and incubated at $37^{\circ} \mathrm{C}$ for 49 days. Tubes signalling positive by day 49 were removed and confirmed for the presence of MAP by IS900 qPCR. Tubes not signalling positive by that time were considered negative.

DNA extraction. A simple, efficient and low-cost method of harvesting MAP DNA based on mechanical cell disruption was used to extract DNA from direct faecal pool samples as well as from a positive MGIT culture tube (Salgado et al 2014). Briefly, a $200 \mu \mathrm{L}$ aliquot of a bacterial suspension from pooled faecal samples or the medium of the MGIT tube was aseptically transferred to $1.5 \mathrm{~mL}$ centrifuge tubes, which were then centrifuged at 5,000 g for $5 \mathrm{~min}$. The supernatant of each tube was discarded, and the opening of the tube was briefly touched with a clean soft paper tissue to remove the remaining liquid. The pellet was disrupted by pipetting with a mixture of $500 \mu \mathrm{L}$ lysis buffer $(2 \mathrm{mM}$ EDTA, $400 \mathrm{mM} \mathrm{NaCl}, 10 \mathrm{mM}$ Tris-HCL pH 8.0, 0.6\% SDS) and $2 \mu \mathrm{L}$ proteinase $\mathrm{K}(10 \mathrm{mg} / \mathrm{mL})$, and then it was transferred to a bead beating tube (BioSpec Products Inc., Bartlesville, OK, USA) containing $200 \mu \mathrm{L}$ of beads (0.1 mm zirconia/silica beads; BioSpec Products Inc., Bartlesville, OK, USA). The tubes were incubated at 56 ${ }^{\circ} \mathrm{C}$ for $2 \mathrm{~h}$ with shaking at $600 \mathrm{rpm}$. The tubes were then shaken in a cell Disrupter (MiniBeadbeater-8; Biospec Products) at 3,200 g for $60 \mathrm{sec}$ and incubated on ice for $10 \mathrm{~min}$. To remove foam and beads from the inner walls, the tubes were centrifuged at $5,000 \times \mathrm{g}$ for $30 \mathrm{sec}$. The samples were briefly vortexed to ensure that any DNA adhering to small solid particles was not lost when the lysate was transferred. All liquid contents from the beadbeating tube were transferred to $1.5-\mathrm{mL}$ microcentrifuge tubes (Eppendorf tubes; Sigma-Aldrich) and $500 \mu \mathrm{L}$ of $100 \%$ ethanol was added. The tubes were left standing for $2 \mathrm{~min}$ at room temperature before being vortexed for 5 seconds and centrifuged at $18,000 \times \mathrm{g}$ for $5 \mathrm{~min}$. at $18{ }^{\circ} \mathrm{C}$. The supernatant was discarded and the pellet was 
washed once in $200 \mu \mathrm{L} 70 \%$ ethanol by resuspension and centrifugation under the same conditions as mentioned above. Next, the pellet was resuspended in $50 \mu \mathrm{L}$ of sterile distilled water. The tubes were placed in a dry heating block (Eppendorf; Germany) at $100{ }^{\circ} \mathrm{C}$ for $5 \mathrm{~min}$. The solution was briefly centrifuged at full speed $(16,000 \times \mathrm{g}$ for $30 \mathrm{sec}$ ) to remove any contaminating material. Finally, a $25-\mu \mathrm{L}$ aliquot of the supernatant was placed into a new Eppendorf tube (Eppendorf tubes; Sigma-Aldrich) to be used as a template for qPCR.

Molecular detection and culture confirmation of MAP by $q P C R$. To detect MAP, either directly from faecal pools or confirmation of positive MGIT tubes, a qPCR protocol previously reported by Salgado et al (2013) was used. Briefly, the target was the insertion element IS900. The qPCR mixture included $5 \mu$ l DNA template, $10 \mu$ l TaqMan Universal Master Mix (Roche, Indianapolis, IN), $0.2 \mu \mathrm{M}$ IS900 primers, $0.1 \mu \mathrm{M}$ probe (Roche, Indianapolis, IN), and water for a total volume of $20 \mu \mathrm{l}$. Primer sequences for IS900, which amplified a 63-nucleotide fragment of the IS900 gene target, were 5'-GACGCGATGATCGAGGAG-3' (left) and 5'-GGGCATGCTCAGGATGAT-3' (right). The probe sequence was TCGCCGCC. The reactions were carried out in a Roche LightCycler System version 2.0 (Roche, Indianapolis, IN, USA) under the following standard conditions: one cycle at $95^{\circ} \mathrm{C}$ for $10 \mathrm{~min} ; 45$ cycles with three steps of $95^{\circ} \mathrm{C}$ for $10 \mathrm{~s}, 60^{\circ} \mathrm{C}$ for $30 \mathrm{~s}$, and $72{ }^{\circ} \mathrm{C}$ for $1 \mathrm{~s}$; and a final cooling step at $40{ }^{\circ} \mathrm{C}$ for $30 \mathrm{~s}$. Negative (Mix and Water PCR-grade) and positive (Mycobacterium avium subsp. paratuberculosis ATCC 19698) PCR controls were included.

\section{STATISTICAL ANALYSIS}

The information collected through the questionnaire and the ELISA test was first analysed descriptively and then analytically. These analyses were carried out using a bivariable and multivariable logistic regression, to explore the influence of multiple flock management practices to MAP seroprevalence. The calculation of the $95 \%$ confidence interval for the prevalence results was performed. Also, the calculation of the true prevalence was made using the WinEpi platform, available at www.winepi.net. An unconditional mixed-effects logistic regression analysis, grouped by flock to account for clustering, was also performed. The criteria of Hosmer-Lemeshow $(P<0.25)$ was used to retain variables for the multivariable model. Statistical analysis was carried out using the Stata 12.0 software (StataCorp LP, College Station, Texas, USA). For the exploration of the influence of multiple flock managements practices to MAP seroprevalence, the unit of analysis was the individual and the case definition of a positive flock was the one that had at least one positive result to the ELISA test, culture or qPCR.

\section{RESULTS}

\section{FLOCK CHARACTERISTICS}

Flock characteristics and management practices explored and then considered as predictors for the risk factor assessment are presented in table 1. The study flocks were all pasture-based and mostly had an area of less than 2 hectares and the flock average population ( $>1$ year) was 155 animals. The flock distribution was composed mainly of small flocks with limited access to veterinary assistance. Katahdin, Dorper and Santa Ines were the predominant breeds. Most of the farms managed other ruminant species in their facilities, mainly cattle, and in $40.3 \%$ of the cases these species shared paddocks. A $61.1 \%$ of the flocks shared roads with neighbouring flocks and $52.6 \%$ spread slurry onto pastures. Purchase of animals was highly frequent in the study flocks. Most of the interviewed owners/managers reported not having heard about the disease before and not having seen paratuberculosis-symptomatic animals in their flocks in the last 2 years.

\section{SEROPREVALENCE}

Eight per cent (37/456, IC: $5.5-10.5)$ of the serum samples were positive, and at least one or more seropositive animals were detected in 70.8\% (17/24, IC: $51.2-90.0)$ of the flocks. Positive ELISA results among regions were 70, 100, and 63.6\% in the Metropolitan Area, Northern and Eastern region of Antioquia, respectively (table 2). The intra-flock seroprevalence ranged from 0 to $21.4 \%$ (data not shown).

\section{FAECAL CULTURE}

Overall, 78.8\% (71/90) of faecal pools showed positive results after confirmation by qPCR. MAP positive pools (one or more) were detected in $83.3 \%$ (IC: 67.3-99.3) of the flocks. The apparent prevalence values among different regions were 100, 67 and 72.7\% in the Metropolitan Area, Northern and Eastern region, respectively (table 3).

\section{qPCR OF FAECAL POOLS}

qPCR informed $25(27,7 \%)$ positive pools out of 90 faecal pools tested. Forty-six per cent (IC: 24.3-67.3) of the flocks showed MAP positive results in one or more of the analysed pools. The apparent prevalence among regions based on qPCR results of pools were 40, 100 and $36,4 \%$ in the Metropolitan Area, Northern and Eastern regions, respectively (table 3 ). 
Table 1. Unconditional analysis of factors associated with the Mycobacterium avium subsp. paratuberculosis ELISA status in 24 flocks of three regions of Antioquia, Colombia.

\begin{tabular}{|c|c|c|c|c|c|c|}
\hline \multirow{2}{*}{ Variable } & \multirow{2}{*}{ Unit/Category } & \multirow{2}{*}{$\begin{array}{l}\text { No of sampled } \\
\text { animals }\end{array}$} & \multirow{2}{*}{$\begin{array}{l}\text { Distribution } \\
(\%)^{*}\end{array}$} & \multicolumn{2}{|c|}{$\begin{array}{c}\text { No ELISA positive } \\
\text { animals }\end{array}$} & \multirow[t]{2}{*}{$\mathrm{P}$} \\
\hline & & & & $\mathrm{n}$ & $\%$ & \\
\hline \multirow{5}{*}{$\begin{array}{l}\text { Flock population } \text { (animals }> \\
1 \text { year) }\end{array}$} & $\leq 70$ & 107 & 23.4 & 14 & 13 & \\
\hline & $71-140$ & 71 & 15.5 & 4 & 5.6 & $0.086^{\mathrm{a}}$ \\
\hline & $141-210$ & 57 & 12.5 & 4 & 7 & $0.191^{\mathrm{a}}$ \\
\hline & $211-280$ & 90 & 19.7 & 7 & 7.7 & $0.172^{\mathrm{a}}$ \\
\hline & $>280$ & 131 & 28.7 & 8 & 6.1 & $0.045^{\mathrm{a}}$ \\
\hline \multirow{3}{*}{ Flock size (hectares) } & $<2$ has & 226 & 49.5 & 16 & 7 & \multirow{3}{*}{0.791} \\
\hline & $\geq 3 \leq 5$ has & 151 & 33.1 & 16 & 10.5 & \\
\hline & $>6$ has & 79 & 17.3 & 5 & 6.3 & \\
\hline \multirow{2}{*}{ Presence of other ruminants } & No & 148 & 32.4 & 15 & 10.1 & \multirow{2}{*}{0.365} \\
\hline & Yes & 308 & 67.5 & 22 & 7.1 & \\
\hline \multirow{2}{*}{ Sharing paddocks } & No & 272 & 59.6 & 17 & 6.2 & \multirow{2}{*}{$0.128^{\mathrm{a}}$} \\
\hline & Yes & 184 & 40.3 & 20 & 10.8 & \\
\hline \multirow{2}{*}{ Sharing roads } & No & 177 & 38.8 & 11 & 6.2 & \multirow{2}{*}{$0.196^{\mathrm{a}}$} \\
\hline & Yes & 279 & 61.1 & 26 & 9.3 & \\
\hline \multirow{2}{*}{$\begin{array}{l}\text { Spreading of manure on } \\
\text { pastures }\end{array}$} & No & 216 & 47.3 & 14 & 6.4 & \multirow{2}{*}{0.260} \\
\hline & Yes & 240 & 52.6 & 23 & 9.5 & \\
\hline \multirow{2}{*}{ Use of dewormer } & No & 100 & 22 & 5 & 5 & \multirow{2}{*}{$0.195^{\mathrm{a}}$} \\
\hline & Yes & 346 & 78 & 32 & 9.2 & \\
\hline \multirow{2}{*}{ Mobilization between flocks } & No & 239 & 52.4 & 21 & 8.7 & \multirow{2}{*}{0.480} \\
\hline & Yes & 217 & 47.5 & 16 & 7.3 & \\
\hline \multirow{2}{*}{ Sheep purchase } & No & 240 & 52.6 & 17 & 7 & \multirow{2}{*}{0.515} \\
\hline & Yes & 216 & 47.3 & 20 & 9.5 & \\
\hline
\end{tabular}

avariables used for the multivariable analysis $(P<0.25)$.

$*$ The distribution refers to the percentage that each value represents.

Table 2. Sheep-level seroprevalence of ovine paratuberculosis infection by ELISA test in three regions of the Province of Antioquia, Colombia.

\begin{tabular}{|c|c|c|c|c|c|c|c|}
\hline Region & Flocks & $\begin{array}{l}\text { Number of } \\
\text { animals }^{\mathrm{a}}\end{array}$ & $\begin{array}{c}\text { Tested } \\
\text { animals }\end{array}$ & $\begin{array}{l}\text { Positive animals } \\
\text { by ELISA }\end{array}$ & $\begin{array}{c}\text { Individual } \\
\text { seroprevalence } \\
(\%)\end{array}$ & $\begin{array}{l}\text { Positive flocks by } \\
\text { ELISA }\end{array}$ & $\begin{array}{c}\text { Flock } \\
\text { seroprevalence } \\
(\%)\end{array}$ \\
\hline Metropolitan Area & 10 & 1012 & 194 & 13 & 6.7 & 7 & 70 \\
\hline Northern & 3 & 323 & 62 & 5 & 8 & 3 & 100 \\
\hline Eastern & 11 & 1144 & 200 & 19 & 9.5 & 7 & 63.6 \\
\hline Total & 24 & 2479 & 456 & 37 & 8.11 & 17 & 70.8 \\
\hline
\end{tabular}

${ }^{a}$ Animal over one year of age.

FACTORS ASSOCIATED WITH THE MAP SEROLOGICAL STATUS

Among the nine risk factors explored in the univariable analysis, four (flock population, sharing paddocks, sharing roads, use of dewormer) were associated with the seropositivity to MAP infection $(P \leq 0.25)$ and were eligible for their inclusion in the final model (table 1).
However, no significant variables were obtained in the final model when the multivariable logistic regression analysis was carried out.

\section{DISCUSSION}

This study was carried out using a combination of direct and indirect diagnostic methods to detect MAP 
Table 3. Flock-level prevalence of MAP infection in sheep by faecal culture and qPCR in three regions of Antioquia, Colombia.

\begin{tabular}{|c|c|c|c|c|c|c|c|c|}
\hline \multirow[b]{2}{*}{ Region } & \multirow[b]{2}{*}{ Flocks } & \multirow[b]{2}{*}{ Pools } & \multicolumn{3}{|c|}{ Faecal culture } & \multicolumn{3}{|c|}{ qPCR } \\
\hline & & & $\begin{array}{l}\text { Positive } \\
\text { pools }\end{array}$ & $\begin{array}{c}\text { Flock } \\
\text { positive } \\
\text { result }^{\mathrm{a}}\end{array}$ & $\begin{array}{c}\text { Flock } \\
\text { apparent } \\
\text { prevalence }\end{array}$ & $\begin{array}{l}\text { Positive } \\
\text { pools }\end{array}$ & $\begin{array}{c}\text { Flock } \\
\text { Positive } \\
\text { result }^{\mathrm{a}}\end{array}$ & $\begin{array}{c}\text { Flock } \\
\text { apparent } \\
\text { Prevalence }\end{array}$ \\
\hline $\begin{array}{l}\text { Metropolitan } \\
\text { Area }\end{array}$ & 10 & 38 & 37 & 10 & 100 & 10 & 4 & 40 \\
\hline Northern & 3 & 13 & 6 & 2 & 67 & 5 & 3 & 100 \\
\hline Eastern & 11 & 39 & 28 & 8 & 72.7 & 10 & 4 & 36.4 \\
\hline Total & 24 & 90 & 71 & 20 & 83.3 & 25 & 11 & 45.8 \\
\hline
\end{tabular}

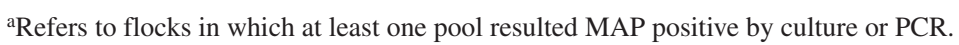

infection in sheep in the Metropolitan Area, Northern and the Eastern regions of the province of Antioquia, Colombia. The combination of ELISA, direct qPCR and faecal culture assured an accurate MAP infection detection in the study regions. To the author's knowledge, this is the first epidemiological report on sheep MAP infection in Colombia, and one of the few studies in Latin America performed in small ruminants to estimate MAP prevalence and to explore management practices associated with MAP seropositivity.

The results show that antibodies against MAP are widespread in the study regions, which in general means that MAP infection had progressed significantly in this animal population, and the serological results indicate a significant proportion of individuals are in the late phase of this infection and, as such, efficient MAP shedders. The latter finding agrees with the results reported elsewhere in the same ruminant species (Attili et al 2011, Stau 2012, Moron-Cedillo et al 2013, Bauman et al 2016a, Morales-Pablos et al 2020). Additionally, the observed flock-level prevalence of MAP infection in sheep flocks could be considered as high, in comparison with what has been reported by Bauman et al $\left(2016^{\mathrm{b}}\right)$ in sheep flocks in Canada, using direct and indirect diagnostic methods (ELISA, bacterial culture and qPCR). According to a systematic review for Latin America and the Caribbean, the prevalence of this infection in sheep is 16\% (7.9-24.1\%) at an individual level, and the prevalence in sheep at the flock level was not reported due to the lack of studies that met the inclusion criteria; the high heterogeneity detected in overall prevalence estimations could be attributed to the high diversity in study design, the variable quality of measures, or the test used (Fernández-Silva et al 2014).

Although no seropositive animals were identified in some flocks (data not shown) in this study. These animals were likely to be found in the early stages of infection and the levels of antibodies may have not been detectable (Nielsen 2010). The location and flock management practices also may limit the contact between neighbouring flocks and different animal species in these regions since the paddocks are distant to each other or the flocks are isolated, and the entry of other animals is not allowed. Nevertheless, MAP infection shows similar behaviour in the study regions, e.g. few seropositive animals being observed within each flock, but many flocks with at least one seropositive animals (Coelho et al 2007, Stau et al 2012, Morales-Pablos et al 2020, Khamassi Khbou et al 2020).

The lower rate of positive results obtained by qPCR in comparison to culture was expected as previously reported (Alinovi et al 2009, Plain et al 2014) for sheep. The different diagnostic sensitivity between qPCR and culture is mainly explained by the fact that the direct qPCR tool has to deal with faecal sample inhibitors for polymerase activity (Monteiro et al 1997, Thornton and Passen 2004) as well as intermittent MAP shedding (Whitlock et al 2000). On the other hand, culture can address these difficulties along the culture period due to the bacteria replication rate (Harris and Barletta 2001). It is well known that liquid media based on Middlebrook 7H9 Broth base such as BACTEC MGIT system has shown better results to grow several strains of Mycobacterium avium subsp. paratuberculosis than conventional media (HEYM) (Gumber and Whittington, 2007). However, the combination of both MAP detection tools improves the capacity of detection of infected flocks.

Even though some flocks showed only negative qPCR and culture results, it is also likely that the results for the tests did not necessarily mean that the animals were not infected, and it may be that the shedding phase has not started (infected animal in a noninfectious phase) yet (McKenna et al 2006, Nielsen 2010). The high MAP prevalence obtained in this study is consistent with what has been previously confirmed for cattle in the same region (Fernández-Silva et al 2011, Ramírez et al 2011, Correa-Valencia et al 2016, Correa-Valencia et al 2019). In addition, the absence of strategies, programs, or projects to prevent or control the infection and the historic management practices that allow the entrance and spread of the infection in the different animal productions help to explain the findings.

The small number of observations and the fit for several factors may explain the lack of association in 
the multivariate linear or logistic regression analysis (Hackshaw 2008, Figueiredo et al 2013). Also, the number of positive and negative outcomes in the observed data influence the precision of the estimates of coefficients in the model. It has been suggested that the dataset should contain a minimum of $10(k+1)$ positive outcomes where $k$ is the number of predictors in the model in order to adequately fit the model (Dohoo et al 2010). These reasons can explain why no significant variables were obtained in the final model.

In the last decade, the arrival of sheep in the study regions has occurred for purposes of restocking and genetic improvement due to the increase of lamb consumption in the region. However, these animals are purchased without quarantine or any diagnostic test. Most of these animals come from different provinces of Colombia where the prevalence of paratuberculosis infections is unknown. In the absence of biosecurity practices, a single animal (clinically or subclinically sick) is enough to infect a flock and disseminate MAP among other flocks. The paratuberculosis prevalence may increase as the biosecurity practices intended for the prevention and control of infection are not being implemented or executed in the flocks (Morales-Pablos et al 2020).

In conclusion, MAP infection is widespread in sheep flocks of the study regions and the combination of several diagnostic tests were necessary to achieve a more accurate diagnosis of MAP infection. Further studies including a larger sample size are needed to identify the risk factors associated with MAP infection in sheep in Colombia.

\section{ACKNOWLEDGEMENTS}

The authors would like to thank the owners of the sheep flocks who enabled us to carry out this study, the Facultad de Ciencias Agrarias of the Universidad de Antioquia, the Laboratorio de Enfermedades Infecciosas, Instituto de Medicina Preventiva Veterinaria, Universidad Austral de Chile, and Colciencias (Convocatoria 761 de 2016: Convocatoria Nacional Jóvenes Investigadores e Innovadores).

\section{CONFLICT OF INTEREST}

The authors declare that they have no conflict of interest.

\section{REFERENCES}

Al-Majali AM, Jawasreh K, Nsour AA. 2008. Epidemiological studies on foot and mouth disease and paratuberculosis in small ruminants in Tafelah and Ma'an, Jordan. Small Rumin Res 78, 197-201.

Alinovi CA, Ward MP, Lin TL, Moore GE, Wu CC. 2009. Real-time PCR, compared to liquid and solid culture media and ELISA, for the detection of Mycobacterium avium ssp. paratuberculosis. Vet Microbiol 136, 177-179.

Angelidou E, Kostoulas P, Leontides L. 2014. Flock-level factors associated with the risk of Mycobacterium avium subsp. paratuberculosis (MAP) infection in Greek dairy goat flocks. Prev Vet Med 117, 233-241.

Attili AR, Ngu Ngwa V, Preziuso S, Pacifici L, Domesi A, et al. 2011. Ovine paratuberculosis: a seroprevalence study in dairy flocks reared in the Marche Region, Italy. Vet Med Int 2011, 1-10.
Bauman CA, Jones-Bitton A, Menzies P, Jansen J, Kelton D. 2016 Paratuberculosis on small ruminant dairy farms in Ontario, Canada: A survey of management practices. Can Vet J 57, 523-530.

Bauman CA, Jones-Bitton A, Menzies P, Toft N, Jansen J, et al. 2016 ${ }^{\mathrm{b}}$ Prevalence of paratuberculosis in the dairy goat and dairy sheep industries in Ontario, Canada. Can Vet J 57, 169-175.

Çetinkaya B, Erdogan H, Morgan K. 1997. Relationships between the presence of Johne's disease and farm and management factors in dairy cattle in England. Prev Vet Med 32, 253-266.

Chiodini RJ, Coffin J, Condon C, Kunimoto D, McFadden JJ. 1993. Abolish Mycobacterium paratuberculosis strain 18. J Clin Microbiol 31, 1956-1958.

Clarke CJ. 1997. The pathology and pathogenesis of paratuberculosis in ruminants and other species. J Comp Pathol. 116, 217-261.

Coelho AC, Pinto ML, Silva S, Coelho AM, Rodrigues J, et al. 2007. Seroprevalence of ovine paratuberculosis infection in the Northeast of Portugal. Small Rumin Res 71, 298-303.

Correa-Valencia N, Ramírez N, Olivera M, Fernández-Silva J. 2016. Milk yield and lactation stage are associated with positive results to ELISA for Mycobacterium avium subsp. paratuberculosis in dairy cows from Northern Antioquia, Colombia: a preliminary study. Trop Anim Health Pro 48, 1191-1200.

Correa-Valencia NM, Ramírez NF, Arango-Sabogal JC, Fecteau G, Fernández-Silva JA. 2019. Prevalence of Mycobacterium avium subsp. paratuberculosis infection in dairy herds in Northern Antioquia (Colombia) and associated risk factors using environmental sampling. Prev Vet Med 170, 1-7.

Dhand NK, Eppleston J, Whittington RJ, Toribio JA. 2007. Risk factors for ovine Johne's disease in infected sheep flocks in Australia. Prev Vet Med 82, 51-71.

Fernández-Silva JA, Abdulmawjood A, Bülte M. 2011. Diagnosis and molecular characterization of Mycobacterium avium subsp. paratuberculosis from dairy cows in Colombia. Vet Med Int 2011, 352561.

Fernández-Silva JA, Correa-Valencia NM, Ramírez NF. 2014. Systematic review of the prevalence of paratuberculosis in cattle, sheep, and goats in Latin America and the Caribbean. Trop Anim Health Pro 46, 1321-1340.

Figueiredo Filho DB, Paranhos R, da Rocha EC, Batista M. da Silva Jr JAD, et al. 2013. When is statistical significance not significant? Brazilian Political Science Review 7, 31-55.

Fiorentino MA, Gioffré A, Cirone K, Morsella C, Alonso B, et al. 2012. First isolation of Mycobacterium avium subsp. paratuberculosis in a dairy goat in Argentina: Pathology and molecular characterization. Small Rum Res 108, 133-136.

Garcia AB, Shalloo L. 2015. Invited review: The economic impact and control of paratuberculosis in cattle. J Dairy Sci 98, 5019-5039.

Gumber S, Whittington RJ. 2007. Comparison of BACTEC 460 and MGIT 960 systems for the culture of Mycobacterium avium subsp. paratuberculosis S strain and observations on the effect of inclusion of ampicillin in culture media to reduce contamination. Vet Microbiol 119, 42-52.

Hackshaw A. 2008. Small studies: Strengths and limitations. Eur Respir J 32, 1141-1143.

Harris NB, Barletta RG. 2001. Mycobacterium avium subsp. paratuberculosis in Veterinary Medicine. Clin Microbiol Rev, 14, 489-512.

Hernández M, García YM, Fernández-Silva JA. 2017. Seroprevalence of Mycobacterium avium ssp. paratuberculosis in small ruminants in a flock in Antioquia, Colombia. Revista Ciencia y Agricultura 14, 51-60.

Khamassi Khbou M, Romdhane R, Sassi L, Amami A, Rekik M, et al. 2020. Seroprevalence of anti-Mycobacterium avium subsp. paratuberculosis antibodies in female sheep in Tunisia. Vet Med Sci 1-6.

Lee A, Griffiths TA, Parab RS, King RK, Dubinsky MC, et al. 2011. Association of Mycobacterium avium subspecies paratuberculosis with Crohn disease in pediatric patients. J Pediatr Gastr Nutr 52, 170-174. 
Mancipe L, Sánchez J, Rodríguez G. 2009. Estudio de la paratuberculosis en un rebaño de ovinos de la sabana de Bogotá mediante la utilización de tres técnicas diagnósticas. Rev Med Vet 18, 33-51.

Marquetoux N, Heuer C, Wilson P, Ridler A, Stevenson M. 2016. Merging DNA typing and network analysis to assess the transmission of paratuberculosis between farms. Prev Vet Med 134, 113-121.

McKenna S, Keefe G, Tiwari A, VanLeeuwen J, Barkema H. 2006. Johne's disease in Canada part II: disease impacts, risk factors, and control programs for dairy producers. Can Vet J 47, 1089-1099.

Mita A, Mori Y, Nakagawa T, Tasaki T, Utiyama K, et al. 2016. Comparison of fecal pooling methods and DNA extraction kits for the detection of Mycobacterium avium subspecies paratuberculosis. Microbiology Open 5, 134-142.

Mogollón G, De Galvis A, Tovar L, Murillo N, Mosses N. 1983. Prevalencia de paratuberculosis ovina en el altiplano cundiboyacense. Revista ICA 18, 479-484.

Monteiro L, Bonnemaison D, Vekris A, Petry KG, Bonnet J, et al. 1997. Complex polysaccharides as PCR inhibitors in feces: Helicobacter pylori model. J Clin Microbiol 35, 995-998.

Morales-Pablos MI, Mejía-Sánchez P, Díaz-Aparicio E, PalomaresResendiz EG, Gutiérrez-Hernández JL, et al. 2020. Risk factors associated with the seroprevalence of paratuberculosis in sheep flocks in the hot-arid region of Sonora, México. Trop Anim Health Pro 52, 1357-1363.

Moron-Cedillo F, Cortez-Romero C, Gallegos-Sanchez J, FigueroaSandoval B, Aquino-Perez G, et al. 2013. Prevalence of Infection by Mycobacterium avium Subspecie paratuberculosis in flocks of sheep of two regions of San Luis Potosi, Mexico. Revista CientificaFacultad De Ciencias Veterinarias 23, 293-299.

Nielsen SS. 2010. Immune-based diagnosis of paratuberculosis Paratuberculosis: organism, disease, control 284-293.

Plain KM, Marsh IB, Waldron AM, Galea F, Whittington AM, et al. 2014. High-throughput direct fecal PCR assay for detection of
Mycobacterium avium subsp. Paratuberculosis in sheep and cattle. J Clin Microbiol 52, 745-757.

Ramírez N, Rodríguez B, Fernández J. 2011. Diagnóstico clínico e histopatológico de paratuberculosis bovina en un hato lechero en Colombia. Revista MVZ Cordoba 16, 2742-2753.

Salgado M, Alfaro M, Salazar F, Troncoso E, Mitchell RM, et al. 2013. Effect of soil slope on the appearance of Mycobacterium avium subsp. Paratuberculosis in water running off grassland soil after application of contaminated slurry. Appl Environ Microbiol 79, 3544-3552.

Salgado M, Verdugo C, Heuer C, Castillo P, Zamorano P. 2014. A Novel low cost method for Mycobacterium avium SUBSP. paratuberculosis DNA extraction from an automated broth culture system for real time PCR comfirmation. J Vet Sci 15, 233-239.

Sechi LA, Dow CT. 2015. Mycobacterium avium ss. paratuberculosis zoonosis - The Hundred Year War - beyond Crohn's Disease. Front Immunol 6, 1-8.

Stau A, Seelig B, Walter D, Schroeder C, Ganter M. 2012. Seroprevalence of Mycobacterium avium subsp. paratuberculosis in small ruminants in Germany. Small Rum Res 105, 361-365.

Sweeney RW. 2011. Pathogenesis of Paratuberculosis. Vet Clin Food Anim 27, 537-546.

Thornton CG, Passen S. 2004. Inhibition of PCR amplification by phytic acid, and treatment of bovine fecal specimens with phytase to reduce inhibition. J Microbioll Methods 59, 43-52.

Whitlock RH, Wells SJ, Sweeney RW, Van Tiem J. 2000. ELISA and fecal culture for paratuberculosis (Johne's disease): Sensitivity and specificity of each method. Vet Microbiol 77, 387-398.

Zarei-Kordshouli F, Geramizadeh B, Khodakaram-Tafti A. 2019. Prevalence of Mycobacterium avium subspecies paratuberculosis IS 900 DNA in biopsy tissues from patients with Crohn's disease: Histopathological and molecular comparison with Johne's disease in Fars province of Iran. BMC Infect Dis 19, 1-11. 